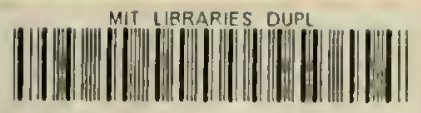

39080 006bb040 8 


.$M 414$

no. 3250-

91

\section{WORKING PAPER \\ ALFRED P. SLOAN SCHOOL OF MANAGEMENT}

Leadership Style and Incentives

Julio J. Rotemberg

Garth Saloner

WP\# 3250-91-EFA September 1990

\section{MASSACHUSETTS \\ INSTITUTE OF TECHNOLOGY \\ 50 MEMORIAL DRIVE \\ CAMBRIDGE, MASSACHUSETTS 02139}


. 


\title{
Leadership Style and Incentives
}

\author{
Julio J. Rotemberg \\ Garth Saloner
}

WP\# 3250-91-EFA

September 1990

(C) 1991 Massachusetts Institute of Technology

Sloan School of Management Massachusetts Institute of Technology

50 Memorial Drive

Cambridge, MA 02139 


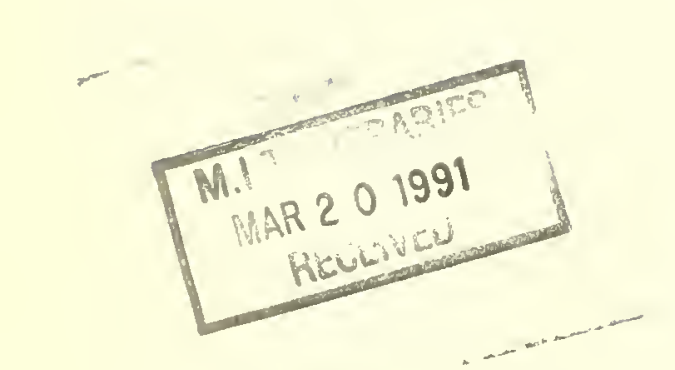




\section{Acknowledgement}

The authors are respectively Professor of Applied Economics at MIT's Sloan School of Management and Professor of Strategic Management and Economics and BP America Faculty Fellow at Stanford University's Graduate School of Business. We wish to thank Tom Allen for help as well as the National Science Foundation and the International Financial Services Research Center at MIT for support. 



\begin{abstract}
We study the relationship between a firm's environment and its optimal leadership style. We present conditions under which firms benefit from having autocratic leadership and conditions under which they benefit from a more participatory style. We use an economic model in which contracts between the firm (or CEO) and managers are incomplete so that providing incentives to subordinates is not straightforward. CEO's with different preferences (or personalities) adopt different leadership styles and these styles in turn have an effect on the incentive contracts that can be offered to subordinates. We show that shareholders gain from appointing a CEO who adopts a participatory style when the firm has the potential for exploiting numerous innovative ideas. By contrast, when the environment is poor in new ideas, shareholders benefit from hiring a CEO whose style is more autocratic.
\end{abstract}


Students of business organizations have long recognized that the heads of different companies exercise their authority in different ways. Some leaders are quite autocratic; they seek and receive only minimal advice from their subordinates. Other leaders are more democratic and seek consensus within their organizations. Some chief executive officers issue directives concerning minute details of operation. Others suggest only broad principles and give considerable autonomy to those below them.

In this paper we provide an economic model in which leadership style has an important effect on firm profitability. We show that senior management's style can alter the incentives that can be provided for subordinates to ferret out profitable opportunities for the firm. The resulting theory has predictions for the circumstances where shareholders benefit from having either autocratic or democratic CEO's.

We consider a setting in which firms undertake investment projects which are sequential in that the firm has the option of shutting down projects mid-way. This is appropriate to a wide variety of business settings: Almost any business venture goes through a variety of stages from conceptualization to eventual adoption and implementation, and a venture can be cut short at any stage by withdrawing the needed additional financing.

As the literature on sequential investment initiated by Roberts and Weitzman (1981) has shown, in such a setting the optimal investment strategy for the firm involves experimenting with the early stages of many projects. Indeed the firm should initiate some projects for which the expected cost if the project if funded to completion exceeds the corresponding expected revenue. The reason is that the option to shut down projects is valuable. 
The challenge to senior management in such a setting is to provide the appropriate incentives for their subordinates to think up and undertake these potentially profitable projects. One simple incentive scheme that the firm can offer is to reward employees whose projects are carried through to fruition. Here, however, the valuable option that the firm has to close projects down mid-way interferes with its ability to provide the appropriate incentives to its managers. In particular, the knowledge that the senior management may abort their projects mid-way reduces the incentive for the subordinates to generate potentially profitable ventures in the first place.

Since the leadership style of the senior management is likely to affect how decisions are made about whether to continue projects already underway, it also affects the ability of the firm to provide incentives for its workers. We investigate the effect that autocratic and democratic leadership styles have on the ability of the firm to provide incentives and study the circumstances in which different leadership styles are optimal.

Our main finding is that in environments which are rich in potential new ideas which the firm could exploit - and where it is correspondingly more important to provide incentives to employees to ferret those ideas out - the democratic leadership style is most attractive. On the other hand, when the environment is less rich in new ideas, autocratic management may be more profitable.

The literature on leadership styles has classified these styles in numerous related ways. Robert Tannenbaum and Warren H. Schmidt (1958), see leadership behavior as falling in a continuum between extreme "boss- centered" leadership and extreme "subordinate-centered" leadership. While the former managers make decisions on their own and announce them the latter insist that each subordinate be allowed to make decisions within broad limits imposed by his/her superior.

Likert (1967) classifies organizations as adopting 4 "systems", labelled 1 through 4 . These systems differ along a variety of characteristics. System 1 is more autocratic in that subordinates are consulted less than systems 2,3 and 4 with system 4 being the one with the most subordinate participation. Managers are increasingly friendlier (and subordinates grow less afraid of their superiors) as one goes from system 1 to 4 .

Without offering as complete a classification, Pascale and Athos (1981) stress similar contrasts. They compare Harold S. Geneen who managed ITT from 1960 to 1979 to the management of Matsushita. Geneen emphasized "unshakeable facts" and obtained these "unshakeable facts" by 
promoting confrontation between line managers and those in charge of staff functions. Geneen is famous for his pressure-cooker meetings where managers has to defend their results in the face ot aggressive questioning by Geneen and other managers. To some extent, these meetings provided subordinates with the ability to express their opinions. However, the unshakeable facts were often then used to remove employees whose performance was less than wholly satisfactory.

The management style at Matsushita was much more participatory. Decision making at Matsushita involved the seeking of consensus and not the unilateral decisions from the CEO. In addition, and perhaps as a result, managerial turnover was much lower since that Japanese company practices lifetime employment. Finally, the company spent considerably more resources developing and training its employees.

The early students of leadership style such as Likert and Tannenbaum and Schmidt suggest that the more participatory leadership style is always better. The alternative view that the optimal style depends on the environment has gained wide currency since the work of Paul $R$. Lawrence and Jay W. Lorsch (1967) and Charles Perrow (1970). These authors focus mostly on the effect of the predictability of tasks. Lawrence and Lorsch put particular stress on the fact that production divisions face relatively predictable tasks while research divisions do not with sales divisions falling some place in the middle. They find that those divisions where tasks are more predictable differ in three respects. The first is that the structure is more formal, there are more rules. The second is that the planning horizons are shorter and the final one is that people are more concerned with getting tasks done than with their interpersonal relations.

Perrow (1970) too focuses on the effect of the extent to which tasks are routine. He argues that the ability to routinize tasks is desirable for firms (because it stabilizes their earnings) and that, when such routinization is possible, bureaucratization ensues as well. When it is impossible, the firm's style is by necessity more participatory.

One issue that is left somewhat open by this research is whether the management style depends on the personality of the leader or whether any CEO can pick any leadership style. In this paper we assume the former. This is supported by the observations of Desmond Graves (1986) who reports the following example (p. 123): "A likable but indecisive leader, who coordinated but did not interfere with the efforts of able subordinates, provided the culture of expansionism necessary for a 
business to make its mark in the marketplace. He was succeeded by one of those subordinates who consolidated the position and quadrupled profitability of the organization in six years..." These characteristics of the leader then permeate the whole organizations' culture, i.e., its basic beliefs about what behavior is appropriate and what behavior is deviant.

Fiedler (1965) also gives great weight to the psychological characteristics of the leader. He shows that leaders who have a more participatitive style also have higher esteem for their coworkers. He regards esteem for co-workers as a personality trait. He concludes that, because different leadership styles are successful in different settings, firms ought to place managers using information on the managers' tendency to esteem their co-workers. While he also studies the effect of the groups' task on the ideal personality of the leader, Fiedler emphasizes that the leader's ideal type depends on the psychological relationship between the leader and his subordinates (i.e., on whether the subordinates like the leader).

Our paper is also closely related to the work based on Coase (1937) which argues that firms arise as a partial solution to the intrinsic incompleteness of contracts between parties. ${ }^{1}$ Firms are seen as creating rights of control and those who are given these rights make those decisions that cannot be contractually stipulated. This solution is generally only partial in that control structures are generally not sufficient to obtain the outcome that is possible with complete contracts. A better outcome would be possible if the universe of available contracts were expanded. For this reason firms do better when, as is proposed by Shleifer and Summers (1987), they hire "fair-minded" CEO's who can be trusted to follow through on implicit promises. Shleifer and Summers' (1987) proposal is similar to ours in that personal characteristics of the CEO matter because contracts are incomplete. The main difference is that "fair-mindedness" is a desirable characteristic for all CEO's whereas we focus on personal characteristics that are appropriate in some contexts and inappropriate in others.

The next section presents our basic model of sequential research and implementation. Section 2 analyzes the model and compares the outcome under two extreme types of CEO. Section 3 formulates and solves the problem of maximizing the fit between the CEO personality and the environment of the enterprise. Section 4 concludes the paper.

\footnotetext{
${ }^{1}$ See Holmstrom and Tirole (1989) for a survey.
} 


\section{The Model}

The situation we examine is one in which a manager can expend effort developing an idea which, if successfully implemented, might improve firm profitability. This effort might entail the search for an improvement in either product design or delivery to the final customer, the investigation of a method to reduce costs, or the development of a new product. Firms obviously differ in their potential for undertaking such profit-enhancing ventures so that only some managers are in a position to pursue them. For example, in mature industries with stable markets and established technologies such opportunities are likely to be rarer than in emerging industries.

We have in mind product enhancements that go through two stages. In the first, the manager invests a great deal of personal time and effort in researching the profit-enhancing idea and developing a proposal for its implementation. The second stage consists of the implementation itself, which may be carried out by the manager or by others. Importantly, however, the final decision as to whether or not to implement the project is in the hands of a more senior manager whom we call the CEO.

The fruits of the manager's efforts are assumed to be stochastic. That is, the potential profit to be reaped by the firm if it eventually implements a manager's project is uncertain at the time that the manager must decide whether or not to put his effort into the project. While some projects will look better than others, the exact profitability of the venture is unknown until the project has been researched by the manager.

\subsection{Notation and Timing}

It is useful to think of events as unfolding over three periods. Managerial effort to develop the idea takes place in the first period. In the second period, the idea is adopted (or implemented). This implementation usually requires that the firm spend additional resources on the project. Finally, in the third period, the implemented project bears fruit. The random variable $\tilde{G}$ denotes the profit of an implemented project from the second period on.

Ignoring discounting, $\tilde{G}$ equals the increased revenue (or reduced cost) in the third period minus the implementation costs incurred in period two. We let the realization $G$ of the random variable $\tilde{G}$ have a cumulative distribution function $F(G)$ and corresponding density function $f(G)$. It is important to stress that the realizations of $\tilde{G}$ can be negative. A negative $G$ simply means 
that the costs of implementing the idea exceed the benefits. The less "rich" the environment in terms of the profit opportinities it presents, the higher the likelihood that $G$ is negative, i.e., the greater is $F(0)$.

For the project with payoff $\tilde{G}$ to become available, the manager must devote effort $e$ to it during the first period: $e=1$ if the manager does explore the idea (devotes effort) and $e=0$ if he does not. At the end of the first period, if the manager bas researched the project $(e=1)$, the potential gain from the project $G$ becomes known to both the manager and the CEO. It is not important for our analysis whether the actual value of $\tilde{G}$ becomes known at the end of the first period or whether the CEO and manager simply have a more accurate estimate of what $G$ will be. For simplicity we assume $G$ becomes known, but the results can be derived by having manager and CEO obtain an estimate, say $G^{e}$, of what $G$ will be.

The CEO must then decide whether or not to implement the project during the second period. We denote the implementation decision by $I: I=1$ if a project is implemented and $I=0$ if it is not. Finally, at the end of the second period, the profit from any project which is researched and implemented is earned by the firm.

\subsection{Preferences and Profits}

We assume that the manager's utility depends only on his effort $e$ and on his income. We break down the manager's compensation into the wage, $w$, for a manager who does not have the opportunity of undertaking a profit-enhancing project and who thus performs only his "usual" tasks, and the "incentive" payment $k$ which is tied to the effort $e$. As we discuss more fully below, we do not let $k$ depend on the actual effort made. It will depend instead on whether the project to which the employee devoted effort is actually implemented. ${ }^{2}$

As is typical in principal-agent models, we suppose that there is some minimum level of $w$ below which the manager will refuse to work. This minimum level of $w$ for performing "normal" tasks can be thought of as being determined in a competitive market for managerial talent.

We assume that the manager's utility is linear in $k$ (so that he is risk-neutral over income in excess of $w$ ) and that exerting the effort $e$ gives him disutility $d .^{3}$ Since we are interested in

\footnotetext{
${ }^{2}$ At the cost of complicating the analysis, we could also have let the manager obtain some direct utility from the implementation of his idea. The improvement in the manager's prospects in the external labor market following implementation of his ides could generate some direct utility of this sort. As long as the expected value of direct utility from implementation does not exceed the disutility of effort $d$ thin modification has no substantive effects on the conelusions.

'Letting the manager's utility be linear in income beyond $w$ implies a form of risk aversion since the worker does not accept
} 
the change in the manager's utility from undertaking projects, we normalize his utility so that his utility when he receives $w$ is zero. Then the manager's expected utility as a function of $k$ and $e$ can simply be written as $u(k, e)=E(k)$ - ed where $E(k)$ is the expectation of $k$.

The focus of our analysis is the utility function of the CEO. In a traditional microeconomic model in which the CEO maximizes profits, the CEO would seek to maximize $I(G-k)$. However we posit instead that the CEO is concerned not only about firm profitability but also about the well-being of the manager. In particular, we suppose that at the time he makes his implementation decision, the CEO places weight $\theta$ on profits and weight $1-\theta$ on the manager's utility. Thus the CEO seeks to maximize:

$$
I[(1-\theta)(G-k)+\theta k]
$$

Note that any effort that might have been expended by the manager prior to the implementation decision is "water under the bridge" and therefore the disutility of that effort doesn't enter the CEO's preferences.

The variable $\theta$ is the key variable in our analysis. It can be though of as representing the "personality type" of the CEO. A CEO with a $\theta$ of 0 is a profit-maximizer: he cares only about the "bottom line" and not at all about the utility of the manager who works for him. A CEO with a $\theta$ that is equal to 1 , in contrast, cares only about the welfare of his manager and is completely oblivious to the "bottom line". Values of $\theta$ between 0 and 1 represent intermediate cases: As $\theta$ increases from 0 to 1 the CEO's concern for profit vis-a-vis his concern for his manager's welfare declines.

We term a CEO for whom $\theta=0$ an "autocratic" manager, and one for whom $\theta=1$ a CEO with a "participatory" style. The motivation for this is the following. We think of the implementation decision generally being taken by the CEO with some degree of consultation with the manager. If the manager's compensation is higher if the project is implemented, as it often will be in equilibrium, the manager will have an incentive to try to convince the CEO that the project should be implemented. The higher is $\theta$, the more the CEO takes the manager's preferences into account. Hence the term "participatory" to describe a CEO with a high $\theta$ By contrast a CEO with

a wage below $w$. This form of risk averaion is not, per se central to our analysis. What is central is that the employee remain an employe and not become the owner of the enterprise. In other words, we cannot let the employee become the residual claimant on all the firm's cash flows. It might be thought that a risk neutral employee would be willing to become the owner. However, thi becomes impossible once it is recognized that a company has many interdependent employees and that they cannot each become the residual claimant of the entire firm. 
a $\theta=0$ does not take the interests or concerns of the manager into account and need not consult with him. Hence the label "autocratic".

In general one might expect that the overall efficiency of the firm would also be affected by the extent to which the CEO is concerned with his manager's welfare. A CEO who cares about his manager's welfare will generally indulge his manager's desire for perquisites and for nonessential equipment and personnel. Since shareholders are probably incapable of stopping all of these payments, we expect autocratic manager to be more efficient. We denote the increase in costs over what they would be under profit-maximization by $C(\theta)$ (so that $C(0) \equiv 0) .^{5}$

In the "background" are the firm's shareholders who have the authority to hire the CEO. Since they are removed from the day to day operations of the firm, they are assumed to be solely interested in profit-maximization and to be unconcerned about the manager's utility as long as he is compensated sufficiently to induce him to do his job. Thus the CEO is the intermediary between the two sets of stakeholders, the manager and the shareholders, and his preferences play a role in determining the sharing of the profits between them.

\subsection{Informational Assumptions and Contractibility}

An important distinction in our model is whether or not the CEO is able to base the manager's compensation directly on the manager's effort. Consistent with the contracting literature ${ }^{6}$ we term the case where the CEO can do so, the "complete contracts" case. One simple condition that makes complete contracts possible is that $e$ be verifiable. It turns out, however, that the outcome with complete contracts based on e can be replicated under somewhat weaker conditions. In particular, it is possible to obtain this outcome as long as $G$ is verifiable.

"Verifiability" means not only that the relevant information is observable by the CEO, but also that it can be established by the body responsible for enforcing the compensation agreement between manager and $\mathrm{CEO}$. In an extreme case this enforcement body might be the Courts in which case verifiability refers to the ability to establish the facts before a judge or jury. More often, however, the enforcement is performed by other employees. If the CEO is observed to have reneged

\footnotetext{
A countervaling force exists when manager and CEO do not observe the actual value of $G$ in the second perjod. Then, a CEO who maximizes profits will tend to opend too much in finding out the true value of $G$. He may, for example, have to appoint separate "task force" to perform this function.

${ }^{3}$ Little hinges on this assumption, and indeed the opposite assumption (that the participatory manager is more efficient) simply involves reinterpreting $C(\theta)$ as ast coving, rather than a cost increase.

See Holmstrom and Tirole (1989).
} 
on an implicit agreement with the manager (for example by withholding payment of a "bonus" when it is understood by the employees that the circumstances warrant a bonus being paid) this has deleterious effects on his reputation for "fair dealing". In this context, verifiability refers to the manager's ability to convince the other employees in the firm that he did indeed carry out the required effort.

Typically $e$ is not verifiable because it is difficult to distinguish cases in which the manager is really putting in the necessary effort and when he is simply going through the motions. Indeed, in the agency literature it is typically assumed that the effort cannot be precisely observed by anyone other than the manager himself.

The fact that $e$ is not observable does not, in and of itself, prevent a complete contract from being written in our setting. Indeed a complete contract will still be possible if $G$ is verifiable. Since the manager is assumed to be risk-neutral, he is indifferent between receiving a direct payment $d$ for exerting effort and receiving a larger payment (which depends on $G$ ) when $G$ turns out to be positive i.e., only in those cases where he in fact comes up with a profitable proposal. Formally, the manager is indifferent between receiving $d$ always and receiving a payment $\phi G$ where $\phi \equiv d / E(G)$. This is because the expected value of $\phi G$ at the beginning of the first period is simply $E(\phi G)=$ $E(k G / E(G))=d$. On average $G$ is a perfect indicator of whether or not the manager exerted the effort and therefore he is as happy to have his compensation based indirectly on the outcome of his effort as directly on the effort itself.

In practice, however, even $G$ is likely to be very difficult to verify. Accounting profit figures are subject to manipulation through the allocation of overhead and other cost items. This manipulation is extremely costly to detect. Moreover, this form of manipulation is not easy to reduce by making partial audits and imposing big fines on firms found to have manipulated their books. The reason is that many of these manipulations are conceivably justified so that it is hard to decide, even ex post the correct procedure for determining costs.

In any event the principal force that ensures that managers receive their incentive payments is probably reputational. When a particular manager has been successful, this becomes known to those that work with him. These also learn whether that employee is treated "unfairly". If the firm treats its employee unfairly, this peer group lets others know. This loss of reputation, in turn, 
makes it harder for the firm to attract new employees. Making payments to the employee depend on $G$ is not possible if other employees do not readily observe $G$. It is for tuis reason that we ignore such contracts.

What peers can easily observe is whether the manager's project is implemented. They can determine this because their contact with the manager lets them know the basic content of the project so the firm is unable to implement the project and pretend that it obtained the idea elsewhere. Thus contracts that make the payment to the manager depend on whether his ideas are implemented are relatively easy to enforce. No outside enforcement party is even needed. It is for this reason that we focus on these contracts.

These contracts differ in one fundamental respect from those contracts studied in the traditional principal-agent literature. ${ }^{7}$ In that literature, as in our model, contracts depend on an a variable which is imperfectly related to effort. The difference is that, in the traditional literature, the variable is manipulable only by the agent who is making the effort. Here, the variable also depends on the decision of the principal who is paying the agent. It is for this reason that the personality of the CEO plays such a crucial role in our analysis.

Since the only action on which the manager's compensation can be made contingent is whether or not the project is implemented, a contract in this incomplete contracts setting consists only of the promise of some payment $k$ if the project is implemented. ${ }^{8}$

Given this contract, managers ought to be keen on having their projects implemented. Empirical evidence on this is unfortunately sparse. Some support comes from the study by Ritti (1968) in which he asks engineers and scientists working in the private sector about their goals and aspirations. Among the engineers, $67 \%$ say that it is very important to work on problems that have practical applications important to their company and $69 \%$ say that it is very important to have the opportunity to help their company increase its profits. Among research scientists, only $28 \%$ deem the latter very important. By contrast, $88 \%$ of the scientists view publication in technical journals as very important. ${ }^{9}$

\footnotetext{
${ }^{7}$ See, for instance, Holmstrom (1979).

- If the idea is not implemented, the manager simply earns his reservation wage $w$. Paying the employee more would be wasteful. Paying him less is impossible given our speciflcation of employee tastes. Our results would still go through if there was no minimum payment but the $k$ has to be thought of as the difference between the payment if the project is implemented and the payments if it is not.

'See also Badawy (1971)
} 
Ritti (1968) views these differences as matters of basic personality. A different interpretation, and one that is consistent with our model, is inat because engineers work on applied problems it is possible to provide them with compensation schemes that depend on the final implementation of their projects. Accordingly engineers do in fact care that their work has valuable practical implications to their company. By contrast, scientists involved in basic research cannot be compensated for the implementation of their ideas. Accordingly, given the incentives they face, they tend to be more concerned with outside recognition than with enhancing the profitability of their firms.

The contract that specifies the contingent payment $k$ is entered into between the CEO and the manager. As discussed above, the "contract" may be implicit rather than explicit, relying on enforcement through reputation rather than litigation. In either case, however, it is subject to the oversight of the shareholders. While the shareholders cannot be expected to monitor the detailed operations of the firm (such as which projects should be implemented and which should not), they can be expected to monitor the broad structure and level of the compensation packages that the managers are offered. ${ }^{10}$ In our model this is captured by assuming that when the contract is specified at the beginning of the first period, the shareholders can object if $k$ is set "too high". Formally, we shall assume that, as profit-maximizers, the shareholders insist that $k$ is set no higher than is absolutely necessary in order to elicit effort.

\footnotetext{
${ }^{10}$ Monitoring by outsiders, be they shareholders via the Board of Directors or other creditors is undoubtedly imperfect and our analysis takes int account some of these imperfections.
} 


\section{Analysis}

\subsection{The Complete Contracts Case}

The case in which the CEO is a profit-maximizer and faces no contracting or informational difficulties (such as where $e$ is contractible) provides a useful benchmark for the more interesting cases that follow. In this case the CEO would be able to induce the manager to research those projects which he wished researched simply by offering the manager a payment of $d$ (the manager's disutility of effort) to undertake the task.

The CEO would therefore instruct the manager to research certain projects. He would then implement any project for which $G \geq 0$. Therefore, the expected net gain from researching a project is:

$$
\int_{0}^{\infty} G d F(G)-d
$$

Note that expression (2) exceeds $E(G)-d$ precisely because the CEO has the option of not implementing projects whose $G$ exceeds zero. Therefore, there exist projects in which $E(G)-d$ is negative which are worth investigating. This is precisely the point of Roberts and Weitzman (1981) who note that, in the case of $R \& D$ projects that can be shut down at a later date, it is worth starting projects which would on average be unprofitable if continued to the end. The reason is that starting a project gives the CEO the option of shutting the project down and this option is worthwhile. What our paper demonstrates is that this option is not as worthwhile once contracts are incomplete.

With complete contracts any project for which (2) is positive is researched and is implemented whenever its realization of $G$ is positive. As discussed above, this outcome can be implemented even if $e$ is not contractible as long as the value of $G$ at the end of the first period (before implementation) is contractible. The possibility we discussed earlier is that the CEO tells the manager he will pay $\operatorname{him} \frac{d}{E(G)} G$. Note, however, that this would induce the manager to exert effort in all projects, including those for which (2) is negative. Thus, the CEO would also have to tell the manager for which projects he will give him this incentive payment.

Another among many schemes for implementing the complete contract involves paying the manager $\frac{d}{1-F(0)}$ whenever $G \geq 0$. Then the average payment to the manager equals $d$ and the manager is willing to make the requisite effort. 


\subsection{The Incomplete Contracts Case}

The difficulty that arises when complete contracts are impossible to enter into can be seen by contemplating the use of a contract analogous to the second one discussed above. In that scheme the manager was effectively only paid when the project was implemented. Suppose that the contract continues to ensure that the manager is paid $\frac{d}{1-F(0)}$ when the project is implemented but that it is not possible to ensure that all projects with $G \geq 0$ are implemented.

At the implementation stage (period 2), the CEO expects the firm to earn additional profits of $G-\frac{d}{1-F(0)}$ if the project is implemented. If the project is not implemented the CEO expects the firm to earn no additional profits, but, since the payment of $d /(1-F(0))$ is contingent on implementation, be also need not compensate the manager for his additional effort. Thus a profit-

maximizing CEO implements projects only if $G \geq \frac{d}{1-F(0)}$. Therefore, in contrast to the complete contracts case, the CEO does not implement those projects for which $0<G<\frac{d}{1-F(0)}$. Some projects which would be profitable were it not for the increased compensation to the manager that their implementation would imply, are not implemented.

The net result is that if the manager exerts the effort he is paid $\frac{d}{1-F(0)}$ only a relatively small fraction of the time. His expected compensation from exerting effort therefore falls short of $d$ with the result that he will choose not to exert the effort, and the project, which on average is profitable, will not be undertaken.

Of course the optimal contract in the complete contracts case is not the optimal contract when contracts must be incomplete. We therefore now examine the optimal contracts in an incomplete contracts setting and contrast the outcomes when there is autocratic and when there is participatory top management.

\subsection{Autocratic Top Management}

With incomplete contracting the CEO can only offer a contract which specifies a payment $k$ which depends on whether the project is implemented. With such a contract in place, the CEO would choose to implement any project for which $G \geq k$. The probability that a project that a manager researches will eventually be implemented is therefore $1-F(k)$. Knowing this, the manager would be willing to exert effort only if

$$
k[1-F(k)] \geq d,
$$


i.e., if his expected increase in utility outweighs the cost of effort.

The lowest cost contract which induces the manager to put in the effort is therefore that with the lowest value of $k$ which satisfies Equation (3). Since both the shareholders and the CEO want to maximize profits in the autocratic case, they are in agreement that the CEO should choose a payment just large enough that the manager's increase in expected utility from exerting effort is exactly equal to his disutility of doing so. This payment by the autocratic CEO to the manager which we denote $k^{a}$ is defined implicitly by

$$
k^{a}\left[1-F\left(k^{a}\right)\right]=d .
$$

Notice that $k^{a}$ must be at least as large as $d$ since $F\left(k^{a}\right) \geq 0$. In the special case where $F(d)=0$, i.e., where the increased profitability of every project exceeds $d$, then $k^{a}$ is equal to $d$. In that case if the manager is paid $d$ if the project is implemented he is certain that every project that he researches will in fact be implemented. Hence he is happy to receive a payment of $d$ contingent on implementation.

If $F(d)>0$, however, so that there exist some projects which ex post will turn out not to be have been worth the manager's effort, then $k^{a}$ will exceed $d$. That is, the profit- maximizing CEO must pay the manager more than his disutility of effort when his project is implemented in order to induce him to research the project in the first place. The reason for this is that the manager realizes that he will only be paid some of the time even if he puts in the effort. In particular, if $0 \leq G \leq k^{a}$ the CEO will choose not to implement the project. Thus the manager insists that he is paid more when he is paid.

This can lead to a difficulty. As the project becomes implemented less often, the manager requires a higher payment when the project is implemented. But, this higher payment leads the CEO to implement the project less often. There might thus exist no payment for which the project is ever implemented, equation (4) might not have a solution.

A necessary condition for (4) to have a solution is that increases in $k$ raise the left hand side of (4). They do so only if $F$ changes relatively slowly as $G$ changes. In particular, the left hand side of (4) rises with $k$ only if the elasticity of $F$ with respect to its argument is smaller than one. If it is bigger, it is impossible to induce the employee to make the necessary effort when management is autocratic. 
Assuming a solution to (4) exists, and given that the CEO implements any project for which $G \geq k^{a}$, the autocratic CEO's firm's expected profits with this optimal contract are given by:

$$
\begin{aligned}
& \int_{k^{a}}^{\infty}\left(G-k^{a}\right) d F(G) \\
& =\int_{k^{a}}^{\infty} G d F(G)-k^{a}\left[1-F\left(k^{a}\right)\right] \\
& =\int_{k^{a}}^{\infty} G d F(G)-d .
\end{aligned}
$$

The second term in (5) reflects the fact that on average the manager is paid $d$. The first term simply represents the average profitability of the project and is the average value of $G$ for a project that is implemented ex post, i.e., the average value of $G$ given that $G \geq k^{a}$. This term is decreasing in $k^{a}$, i.e., the higher is $k^{a}$ the lower are the expected profits from undertaking the project in the first place. This is because as $k^{a}$ rises it becomes increasingly more likely that the CEO will ultimately choose to implement the project, even when it turns out that $G>0$.

Comparing (2) and (5), the expected payment to the manager is $d$ both in the complete contracts case and this incomplete contracts autocratic CEO case. However, the increase in expected profits to the firm are lower with incomplete contracts by

$$
\int_{0}^{k^{a}} G d F(G)
$$

This is because the firm loses those profit opportunities where $0 \leq G \leq k^{a}$.

These lost profit opportunities can sometimes be sufficient to eliminate altogether the benefits from exploring the project. The solution to (4), assuming it exists, will often involve a high value of $k^{a}$. This occurs in particular when $[1-F(d)]$ is small, i.e., if a relatively small fraction of the projects are worth doing. However, it is apparent from (5) that if $k^{a}$ gets "too large" it may not be worthwhile to have the manager exert the effort in the first place: the firm may not be able to exploit its possible profitable opportunities at all. This can occur even if it would be worthwhile to undertake the project with complete contracts.

\subsection{Participatory Management}

In the second period the participatory CEO, who cares only about the manager's utility, will implement any project which is recommended to him. Thus if the contingent payment $k$ in the 
participatory management case is denoted $k^{p}$, the manager will undertake the project provided $\stackrel{p}{\sim}>d$.

Since the shareholders will not tolerate a level of compensation for the manager that is in excess of what is required to elicit effort, the CEO must set $k^{p}=d$ (even though the CEO would prefer an even higher level of compensation!). The net result is that the project is undertaken regardless of its merits, and the manager is paid $d$. The shareholders profits are therefore

$$
E(G)-d-C(0)
$$

Participatory management has two disadvantages vis-a-vis profit- maximization with complete contracts. First, this regime is less efficient if $C(0)>0$. Second, the participatory CEO implements projects even if they are not worthwhile $(G<0)$. Thus, ignoring $C(0)$, the net benefits from the project equal $E(G)-d$. As discussed above, this is the value of the project when the CEO gives up his option to shut down unprofitable projects.

\subsection{Autocracy and Participation Compared}

Despite the differences in the preferences of the CEO in the two regimes, because of the oversight imposed by the shareholders, the manager's expected compensation is identical. The shareholder's profits differ however. The difference between expected profits under participation and autocracy is given by:

$$
\begin{aligned}
\Delta & \equiv\left[G^{0}-d-C(0)\right]-\left[\int_{k^{e}}^{\infty} G d F(G)-d-C(0)\right] \\
& =\int_{-\infty}^{k^{a}} G d F(G)-C(0) .
\end{aligned}
$$

The sign of $\Delta$ is ambiguous in general. The inefficiency of participation obviously weighs the scales in favor of autocracy. Apart from the effect of $C(0)$, however, which regime dominates is ambiguous: the sign of the first term in (8) is ambiguous. That is, even if the autocratic CEO is less efficient at carrying out the operations of the firm, he may nonetheless produce fewer profits than a non-profit-maximizing participatory CEO!

The intuition for this result is the following. As long as the manager stands to gain if the CEO implements his project, the participatory CEO will implement it, regardless of the profit consequences because he values the manager's preferences and not profit. As a result, the manager can easily be induced to undertake his project, and the net result is that every project is researched 
and implemented. While this means that some unprofitable projects are implemented, it also means that all of the profitable ones are too.

The profit-maximizing autocrat is unable to achieve this outcome. Both he and the manager understand that as long as the $\mathrm{CEO}$ is required to compensate the manager if he implements his project, the CEO will have an incentive not to implement some projects. In particular, the CEO will not implement projects which would be profitable but for the manager's compensation. However, this problem then feeds on itself. Knowing that he will only be compensated for some fraction of the projects that he researches, the manager demands a high rate of compensation for those which are implemented and on which he is thereby compensated. This in turn reduces the incentive for the CEO to implement the project, since the expected profit threshold that the project must achieve is higher.

The net result of this is that some profitable projects are foregone. Even if the autocratic CEO would make higher profits if he had a participatory style, and therefore be better off himself, there is nothing he can do about it. While he would like to promise to respect only his manager's desires and ignore profits in the second period, his inability to credibly commit to such a promise renders the promise ineffectual.

To see when the participatory style dominates it is useful to decompose $\Delta$ as follows:

$$
\Delta=\int_{0}^{k^{a}} G d F(G)+\int_{-\infty}^{0} G d F(G)-C(0) .
$$

The first term demonstrates the advantage of participation: for projects in the range $0<G<k^{a}$ participation ensures that profitable projects are implemented whereas they are not implemented under autocracy. Conversely, the second term illustrates the relative advantage of autocracy: unprofitable projects which are adopted under participation are not adopted under autocracy.

The effect of the first two terms of (9) is demonstrated in Figure 1. As that figure shows, when the proportion of projects with $G<0$ is low, the participatory style is particularly attractive. It is in this region that the effect of the CEO's overindulgence of his manager's pursuit of unprofitable projects is felt, and where the autocrats intolerance for ex post unprofitable projects is costly. Thus a participatory management style is particularly attractive in environments which are relatively rich in available profitable opportunities.

Autocratic management is particularly attractive when $d$ is small relative to the possible $G$ 's. 
From Equation (4), $k^{a}$ is positively related to $d$. In the limit if $d=0$ then $k^{a}=0$ as well. Thus the smaller is $d$ the smaller is the region in which the autocratic CEO foregoes profitable opportunities. Then his operating efficiency and intolerance for unprofitable projects are assets to the shareholders. Therefore if the manager's disutility for effort is small compared to the potential gains from his effort, autocracy is likely to dominate the participatory style.

Notice too that to the right of $k^{\mathfrak{a}}$ in Figure 1 the two regimes are equivalent, except that autocracy is more efficient. This has two related implications. First, if the entire distribution of $G$ lies to the right of $d$ so that every project that is researched will be implemented, the more efficient autocratic CEO will be more profitable.

Autocracy is also attractive in the other extreme where there are essentially no worthwhile projects. In this case, few projects will be researched in either regime and the third term in (9) will weigh against the participatory style.

By contrast, any change in the distribution which results in less weight in "the tails" and more weight in the middle region $\left[0, k^{a}\right]$ will be more suited to participatory management. That is, if an outcome in the region $\left[0, k^{\mathfrak{a}}\right]$ becomes more likely and an outcome below 0 becomes correspondingly less likely, the participatory style becomes more attractive.

So far our analysis has dealt with the management style that is more profitable for any one project. Firms, on the other hand, have access to many different projects whose distribution functions differ. However, we can use the results from this section to make inferences about the style of management that is suited to particular firms. In particular, firms which face more projects whose distribution functions have substantial weight in the middle region where many new ideas are worthwhile but not revolutionary benefit from participatory management. Insofar this distribution is the typical one in areas rich with potentially profitable innovations, we should see innovative firms being participatory.

What is more, as Pascale and Athos (1981) report for Matsushita, such firms will benefit disproportionately from training their employees. Such training presumably costs resources while also facilitating the exploration of new ideas. Insofar the autocratic style does not reap as many of the benefits from new ideas, shareholders do not benefit from training the employees whose CEO's are autocratic. Put differently, if training increases the odds that the employee will be in a position 
to explore ideas whose payoff tends to lie in the region $\left[0, k^{\alpha}\right]$, then such training is attractive if the CEO is participatory and unattractive otherwise.

\section{The Best Manager For the Job}

Thus far we have contrasted the autocratic and participatory management styles and have discussed the circumstances under which each style is the preferred one. The main result so far is that profit-maximizing shareholders may choose to hire a non-profit-maximizing CEO. In this section we go one step further and suppose that the shareholders can choose among candidate CEO's with different personalities as measured by their concern for their workers. That is, we suppose that the shareholders can choose a CEO whose personal " $\theta$ " is best suited to the environment in which the firm operates.

In order to do this we examine how shareholder profitability varies with $\theta$. Suppose that the CEO is of type $\theta$ and that the manager is offered a contract which pays him $k^{\theta}$ if his project is implemented.

In that case, in the second period the CEO will choose to implement a project that the manager has researched if:

$$
\begin{aligned}
(1-\theta)\left(G-k^{\theta}\right)+\theta k^{\theta} & \geq 0 \\
\text { That is, if } \quad G & \geq\left(\frac{1-2 \theta}{1-\theta}\right) k^{\theta} .
\end{aligned}
$$

Knowing this, the manager will be willing to exert effort ( $\operatorname{set} e=1$ ) during the first period if his expected future payments exceed his disutility of effort. That is, if:

$$
\begin{array}{r}
\int_{\left(\frac{1-2 \theta}{1-\theta}\right) k^{\theta}}^{\infty} k^{\theta} d F(G) \geq d \\
\text { i.e., if }\left[1-F\left(\left(\frac{1-2 \theta}{1-\theta}\right) k^{\theta}\right] k^{\theta} \geq d .\right.
\end{array}
$$

Since the shareholders insist that the manager be paid no more than is absolutely essential in order to induce him to work, they require that Equation (11) be made to hold exactly, i.e., the optimal $k^{\theta}$, which we denote $k^{\theta *}$, is that for which

$$
\left[1-F\left(\left(\frac{1-2 \theta}{1-\theta}\right) k^{\theta *}\right)\right] k^{\theta \cdot}=d
$$


The firm's expected profits are then given by:

$$
\int_{\left(\frac{1-2 \theta}{1-\theta^{\theta}}\right) k^{\theta}}^{\infty}\left(G-k^{\theta \cdot}\right) d F(G)-C(\theta),
$$

which, using (12), can be written as:

$$
\begin{gathered}
\int_{\left(\frac{1-2 \theta}{1-\theta}\right) k^{\theta \cdot}}^{\infty} G d F(G)-\left[1-F\left(k^{\theta *}\right)\right] k^{\theta *}-C(\theta), \\
=\int_{\left(\frac{1-2 \theta}{1-\theta}\right) k^{\theta}}^{\infty} G d F(G)-d-C(\theta) .
\end{gathered}
$$

Notice first that the autocratic and participatory extremes are indeed special cases of this more general formulation. If $\theta=0$, the autocratic case, then $k^{\theta *} \equiv k^{a}$ from equation (12) (since $\left(\frac{1-2 \theta}{1-\theta}\right)=1$ in this case). But then the expression for expected profits in equation (14) is identical to that for the autocratic case, in equation (5).

Similarly, the participatory case is approached as the limit as $\theta \rightarrow 1$. Then, $\left(\frac{1-2 \theta}{1-\theta}\right) \rightarrow-\infty$ so that the expression for expected profits in equation (14) reduces to that for the participatory style given in equation (7). Two terms in equation (14) depend on $\theta$, the integral and $C(\theta)$. Consider the integral first. The integral reaches a maximum when the lower limit of the integral is zero. If the lower limit is any lower, negative-profit projects are included; if the lower limit is any higher, positive profit projects are excluded. How the integral varies as $\theta$ varies therefore depends on how the lower limit varies with $\theta$. In fact it is straightforward to show that the lower limit is strictly decreasing in $\theta$ and that it is equal to zero when $\theta=\frac{1}{2} \cdot{ }^{11}$

The value of the integral as a function of $\theta$ is therefore as represented in Figure 2. $C(\theta)$ which is increasing in $\theta$ is also depicted there.

If there is no difference in efficiency across regimes, that is $C(\theta)$ is the same for all $\theta$, then profits are maximized if $\theta=\frac{1}{2}$ : The "best" $\mathrm{CEO}$ is one who cares equally about profits and his manager's utility.

The intuition for this is that at the implementation stage the CEO cares as much about the benefit that the manager obtains from his additional compensation as he cares about the effect of that compensation on the profitability of the firm. Overall, therefore, he does not care about the

\footnotetext{
${ }^{11}$ To see this notice that $\frac{d}{d \theta}\left(\frac{1-2 \theta}{1-\theta}\right)=\frac{-1}{(1-\theta)^{2}}<0,80$ that $\left(\frac{1-2 \theta}{1-\theta}\right)$ is a decreasing function of $\theta$ which is equal to 1 when $\theta=0$, is positive when $k^{\theta}<\frac{1}{2}$, and negative thereafter. The term $k^{\theta *}$ is positive, and from (12), is decreasing in $\theta$. Therefore the lower limit, which is the product of $\left(\frac{1-2 \theta}{1-\theta}\right)$ and $k^{\theta *}$ is atrictly decreasing in $\theta$ and is zero when $\theta=\frac{1}{2}$.
} 
manager's compensation but, instead, worries only about whether $G>0$ : i.e., whether or not the profits of the firm will increase as a result of implementing the project.

Thus the CEO's ex post incentives are optimal: he implements exactly those projects which should be implemented from a profit-maximizing point of view. The manager's compensation is then set so that he is willing to exert the effort necessary to research the project even though the project will only be implemented if it turns out to be profitable. The overall outcome is identical to that which would be achieved if the firm were able to write a complete contract with the manager.

One can also see from Figure 2 that if $C(\theta)$ is increasing in $\theta$, the optimal $\theta$ for the firm, $\theta^{*}$, is strictly less than $\frac{1}{2}$. Thus the firm should lean in the direction of autocracy (from $\theta=\frac{1}{2}$ ) when the participatory style is less efficient in conducting the day-to-day operations. The extent to which it should do so depends on the distribution function $F$. It is for this reason that different firms must in general have CEO's with different personalities. One interesting implication of our analysis is that, in general, the purely autocratic and the purely participatory styles are both suboptimal. This will be true unless the function $C$ rises very fast with $\theta$ in which case it is possible for pure autocracy to be optimal.

The management style, and hence the $\theta$ that firms choose obviously affects the range of projects that the firm should seek to explore. In other words it affects that range of projects for which (14) is positive. The investment rules derived by Roberts and Weitzman (1981) apply only in the case of complete contracts and that they have to be suitably modified depending on the management style of the firm.

\section{Conclusions}

We have presented a model where shareholders select the firm's leadership style to maximize ex ante profits. This leadership style affects the corporate culture of the organization in that employee's beliefs about how they will be treated in various circumstances depend on this leadership style. In the model, maximization of ex ante profits sometimes requires that the firm not be too keen on maximizing ex post profits. Leadership style matters because it can achieve this aim.

In our setup, we have followed Fiedler (1965) and Graves (1986) in making leadership style depend on the personality of the chief executive. This is not an essential assumption. In particular, we could have imagined that firms develop reputations for having certain styles as in Kreps (1984). 
Thus managers of certain firms would foster a participatory style simply because abandoning that style (by making a decision that the managers dislike) would cause a loss of reputation. This would be more in line with Perrow (1970)'s view that corporate culture depends mostly on interaction between people and is relatively unrelated to their psychological characteristics. Since even Kreps (1984)' construct relies on small probabilities of having an "irrational" personality, it seems more straightforward to give personality a more central role as we (and Shleifer and Summers (1987)) do.

The principal open question left by this research is its empirical relevance. To what extent does the distinction between participatory and autocratic styles help us understand the effectiveness of research inside of firms? To what extent are these differences in leadership style the clever responses of executives to their environments and to what extent do they hinge on the personality of the CEO?

Fiedler (1965) shows that the extent to which the leader gives a favorable description of his least preferred co-worker is positively correlated with the permissiveness and human-relations orientation of the leader. He also shows that leaders who give such favorable descriptions tend to be more successful in decision and policy making teams and in groups that have a creative task. These activities certainly seem to involve more research of the type that we have considered than the groups in which the more autocratic leaders performed well. These latter groups include basketball and surveying teams, open hearth shops and military combat crews. One question that is left open by Fiedler's research is whether the regard one has for one's least favored co-worker is a feature of one's personality or whether it is molded by the work environment.

Miller, DeVries and Toulouse (1982) and Miller and Toulouse (1986) study more directly the extent to which CEO personality affects both strategy (i.e., whether the firms are innovative) and structure (i.e., whether the firms are autocratic). Miller and Toulouse (1986) consider three personality traits. The first is locus of control. Individuals with internal locus of control feel that what happens to them is the result of their own actions while those with more external locus of control tend to view their environment as having a larger role in shaping their life. Miller and Toulouse report that firms whose executives have an internal locus of control tend to innovate more and also tend to delegate more. The relationship between locus of control and innovation is statistically very significant while that between locus of control and delegation is significant only 
at the $10 \%$ level.

Another personality attribute they consider is flexibility. Those who are flexible are adventurous and adapt easily, those who are not tend to be more rigid. According to their study, CEO's whose personality is more fiexible tend to lead firms that innovate and delegate more though only the latter relationship is statistically significant. The finding that there exist personality traits which leads to both more innovation and more delegation seems broadly consistent with our theory if one views most innovations as being the result of research whose payoff tends to lie in the "middle" region $\left[0, k^{a}\right]$.

Finally, Miller and Toulouse (1986) consider need for achievement (nAch) of various executives. Individuals with high nAch set relatively difficult goals for themselves and try to achieve them with little outside help. Miller and Toulouse show that executives with a high need for achievement tend to lead innovative firms that delegate little. This seems inconsistent with our story that innovative firms delegate. However, closer inspection of their results show that this correlation is true only for small frms. Thus they seem to be picking up the existence of individual innovators whose need for achievement is high and, in part as a result, succeed in creating viable companies. This is not inconsistent with our theory if these innovations are made by the CEO himself. Our theory implies that delegation helps subordinates (not the CEO) to be innovative.

One of the reasons the results of Miller, DeVries and Toulouse (1982) and Miller and Toulouse (1986) are only partial is that they focus on different psychological traits than those that emerge naturally from our theory. In our theory, what is important is the extent to which a CEO cares for the welfare of his employees. This might well be measurable by some index of empathy like the one proposed by Mehrabian and Epstein (1972). Mehrabian and Epstein (1972) report that subjects whose index of empathy was high were also willing to spent more time helping others. This suggests that it is quite possible that CEOs measuring high on this index might want to treat their employees well. Thus one implication of our theory is that firms that do relatively well in innovative sectors ought to have CEO's with a high index of empathy, holding everything else constant. 


\section{References}

Badawy, M.K.: "Industrial Scientists and Engineers: Motivational Style Differences," California Management Review, Fall 1971, 11-16.

Buss, Arnold H. and Stephen E. Finn: "Classification of Personality Traits, Journal of Personality and Social Psychology,52, 1987, 432-44.

Coase, Ronald: "The nature of The Firm, "Economica, November 1937, pp. 386-405.

Fiedler, Fred E.: "Engineer the Job to Fit the Manager," Harvard Business Review, 43, Sept.Oct. 1965, 115-22.

Graves, Desmond:Corporate Culture - Diagnosis and Change, St Martin's Press, 1986.

Holmstrom, Bengt: "Moral Hazard and Observability," Bell Journal of Economics, Spring 1979, 74-91.

- and Jean Tirole: "The Theory of the Firm" in Richard Schmalensee and Robert Willig Handbook of Industrial Organization, North Holland, 1989.

Kreps, David: "Corporate Culture and Economic Theory," Working Paper, May 1984.

Lawrence, Paul R. and Jay W. Lorsch Organization and Environment Harvard Business School Press, 1967.

Likert, Rensis: Human Organization, McGraw-Hill, 1967.

Mehrabian, Albert and Norman Epstein: "A Measure of Emotional Empathy," Journal of Per. sonality, 40, 1972, 525-43.

Miller, Danny, Manfred F.R. Kets DeVries and Jean-Marie Toulouse: "Top Executive Locus of Control and its Relationship to Strategy Making, Structure, and Environment", Academy of Management Journal. 1982, vol. 25, pp. 237-253.

Miller, Danny and Jean-Marie Toulouse: "Chief Executive Personality and Corporate Strategy and Structure in Small FIrms", Management Science, vol. 32, Nov. 1986, pp. 1389-1409. 
Pascale, Richard T. and Anthony G. Athos The Art of Japanese Management, Warner Books, 1981.

Perrow, Charles: Organizational Analysis: A Sociological View, Wadisworth publishing, 1970.

Roberts, Kevin and Martin L. Weitzman: "Funding Criteria for Research, Development and Exploration Projects," Econometrica, 49, September 1981, 1261-88.

Ritti, Richard:"Work Goals of Scientists and Engineers," Industrial Relations, Feb 1968, 118-31.

Shleifer, Andrei and Lawrence H. Summers: "Breach of Trust in Corporate Takeovers", 1987.

Tannenbaum, Robert and Warren H. Schmidt "How to Choose a Leadership Pattern," Harvard Business Review, 96, March-April 1958 


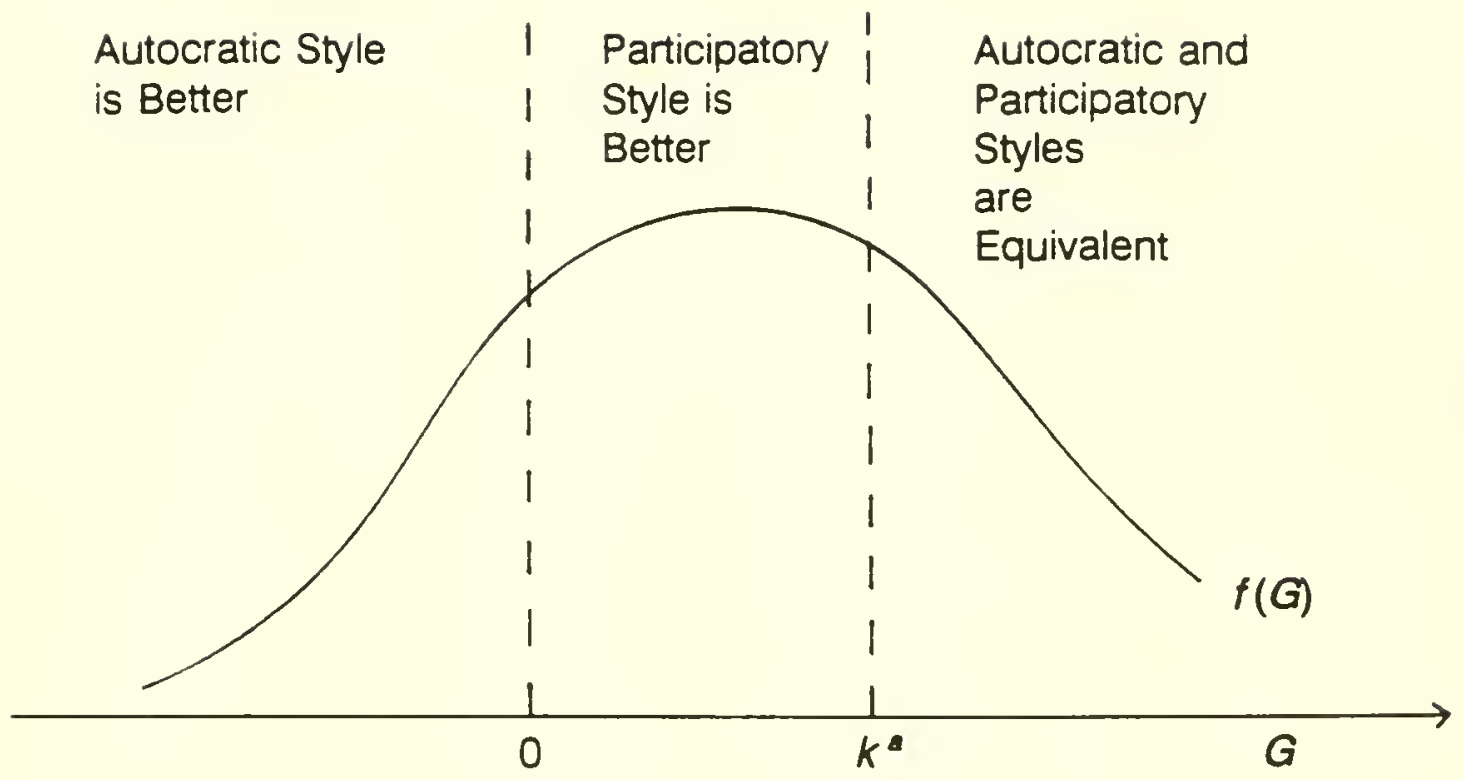

Figure 1: Comparison of Autocratic and Participatory Styles for the Case Where $C(\theta)$ is Zero 


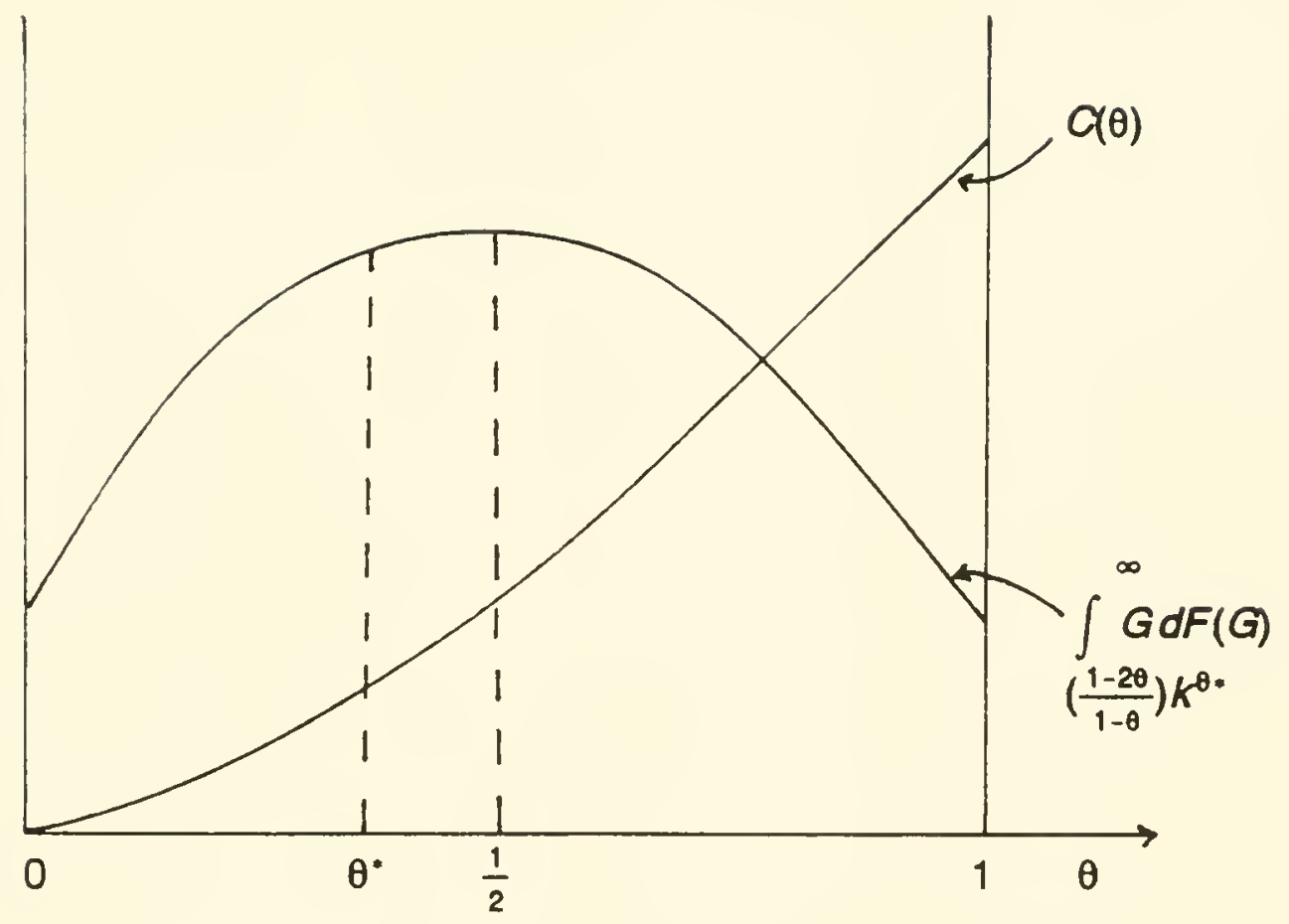

Figure 2: The Optimal Value of $\theta$ 



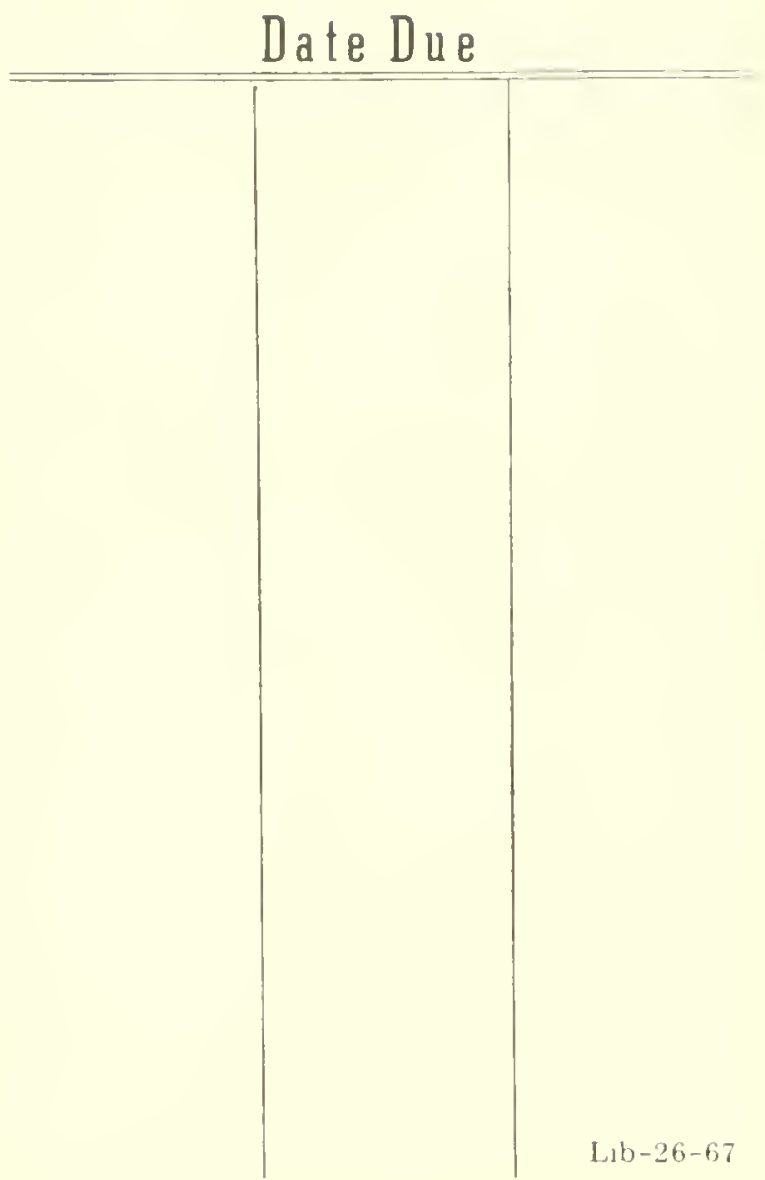




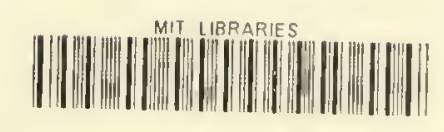

39080 006bb040 8 
140

(1)

Hentand

(a)

4.

(n)

(1)

3.t.

\section{(1)}

Hown

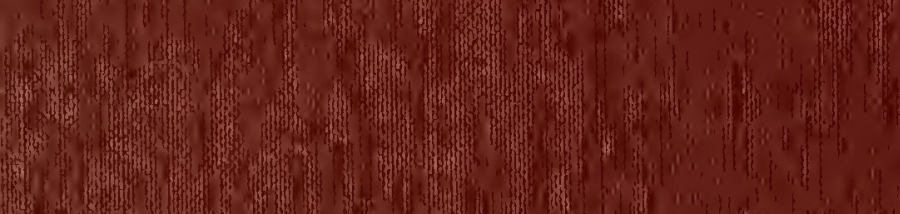

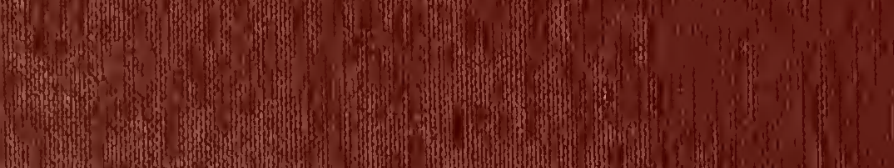

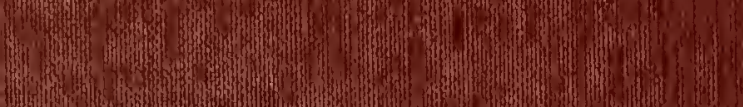

